\title{
FLEXURAL STRENGTH OF WEATHERED GRANITES UNDER WETTING - DRYING CYCLES: IMPLICATIONS TO STEEL STRUCTURES
}

\author{
Sarkar Noor-E-Khuda ${ }^{1, *}$ and Faris Albermani ${ }^{2}$ \\ ${ }^{1}$ School of Engineering and Technology, Central Queensland University, Perth, Australia \\ ${ }^{2}$ School of Engineering and Technology, Central Queensland University, Mackay,, Australia \\ *(Corresponding author: E-mail: s.noorekhuda@cqu.edu.au)
}

\section{A B S T R A C T}

Deterioration of stone veneer cladding panels due to environmental weathering can lead to expensive restoration work, serious risks from falling debris and compromises the performance of high-rise steel and concrete structures. The influence of wetting - drying cycles (WDC) on the flexural tensile strength of thin granite cladding panels is investigated. Forty-five specimens of Imperial Black, Calca and Grandee type Australian granite panels were used in the experimental program. Total 15 specimens served as control reference, while 30 specimens were subjected to 100 WDC in two separate stages. The wetting cycles were conducted in contact with tapwater and acidified solution of $\mathrm{pH} \approx 4.5$, while the drying cycles were conducted using a controlled drying chamber at $40{ }^{\circ} \mathrm{C}$. Ultrasonic pulse velocity (UPV) and flexural tensile strength of the control, and weathered specimens were measured after the 50th and 100th weathering cycle of WDC. It was noticed that the thin granite cladding panels experienced limited flexural strength reduction accompanied by changes in UPV and weight loss. A correlation between flexural strength and UPV of the unweathered and weathered WDC specimens is proposed which can be useful in on-site assessment of granite cladding panels during the service life of the primary steel structure.
A R T I C LE H I S T O RY

$\begin{array}{ll}\text { Received: } & 27 \text { February } 2018 \\ \text { Revised: } & 20 \text { October } 2018 \\ \text { Accepted: } & 25 \text { October } 2018\end{array}$

\section{K E Y W O R D S}

Ultrasonic pulse velocity;

Wetting - drying cycles;

Granite;

Flexural strength;

Weight loss

\section{Introduction}

With the advent of modern building technologies such as the skeletal steel frame system, bearing walls have given way to curtain walls, and thick stone walls are often replaced by thin stone structural veneer cladding panels while retaining the masonry appearance of the structure. Damage and deterioration of the stone veneer cladding panels due to environmental weathering (physical, chemical and biological) and improper design can lead to expensive restoration work as well as serious risks from falling debris [1]. Numerous incidents of façade/cladding failure due to deterioration of the stone cladding panels and collapse/corrosion of the supporting steel/aluminium anchorage system have been reported around the world [1-5]. With the recent fire safety concerns regarding aluminium sandwich panels cladding on tall buildings around the world, it is expected that a renewed interest will emerge in the use of thin granite veneer cladding as an alternative safe façade solution on existing and new highrise buildings.

The veneer cladding system installed on a steel or concrete frame structure is usually a non-loadbearing system. Attention to detailing, anchor design and panel size selection is required to eliminate possible secondary stresses resulting from coupling between the primary structure and the cladding system. Two type of metal anchoring systems are usually utilised to attach thin granite veneers panels to the frame. These are; kerf anchors and rear fixed pin anchors. Kerf anchor requires attachment of a metal bracket to a slot cut into the edge of the granite panel. An inclined stainless steel pin is usually attached to the rear face of the panel when a rear fixed pin anchor is used [1].

Granite is the most preferred natural stone for thin structural veneer claddings (Pires et al. [4]). Being structurally superior over other stone veneers, granite received fewer research attention. As thin structural veneer claddings are usually installed on the exterior of buildings, they inevitably are subjected to environmental weathering [5]. It is therefore important to quantify the design strength of the granite veneer cladding panels and the effect of wetting-drying cycles on the strength. This will lead to better design and less failure incidents. Although granite veneer panels are used as a cladding, and seldom considered as a structural element, being thin panels raise concern over its flexural capacity under wind loading. Whether the flexural strength of thin granite veneer cladding panels is influenced by wetting-drying cycles (WDC) has not been widely addressed.

The anisotropic material properties of granite depend heavily on the general geology at the source, and the local geological features at the scale of fissures and cleavage planes which can alter due to weathering. Material characterisation of the thin granite panels through destructive testing such as four-point bending test (which is preferred in conventional engineering practice) can be impractical, considering the wide variety of granites available. Moreover, the results obtained through random samples from a particular batch may fail to represent the other available granite types, which means individual tests have to be conducted on each variety/batch. Alternatively, a less costly investigation can be carried out using non-destructive testing (NDT) techniques. Among the NDT techniques the ultrasonic pulse velocity (UPV) has facilitated in detailed examination of civil structures [6], material characterisation and damage detection [7 - 10], and health monitoring [11,12]. Vasconcelos et al. [8] and Chen et al. [10] successfully assessed the strength, stiffness and fracture energy of granite, and estimated crack depth, direction and thickness of damaged surface layers, respectively using UPV.

A number of studies have reported of the variation in mechanical properties of thin structural stone veneers due to freezing/thawing [5], salt crystallisation [12], wetting/flooding [13], heating [14] and simulated acid rain [15]. Franzoni and Sassoni [15] tested several limestone, sandstone and marble specimens (of different microstructural characteristics) in a simulated acid rain test. It was shown that all the stone specimens experienced higher weight loss with increased acidity of the solution and exposure duration, which indicates possible alteration of the internal grain structure/fissure/micro-cracks and degradation of the mechanical strength properties. Vasconcelos et al. [8], from series of destructive and non-destructive tests, derived the direct tensile and compressive strength of granite specimens and proposed correlation between the strength parameters and UPV. It was shown that the direct tensile strength of granite increased exponentially and the compressive strength increased linearly, with UPV. Noor-E-Khuda et al. [5] proposed a linear relation between flexural strength and UPV for thin granite cladding panels subjected to accelerated freeze-thaw cycles (FTC). The study also showed that the commonly used Australian granite cladding panels suffered a considerable loss of flexural strength under FTC. This has prompted the current investigation to assess the influence of wetting - drying cycles on the flexural strength of the same types of Australian granite cladding panels.

Moisture change that occurs under cyclic wetting and drying can weaken the overlying rock by expansion and contraction. Water itself is a good solvent and is known to be the principal agent in physical/chemical weathering. It provides, a medium in which reactions can occur at a faster rate (reactions are usually faster in liquid phase than in solid phase) and a medium of transport to remove the reaction products and perpetuating a state of inequillibrium (promoting the forward reaction to take place). Hence, the duration of wetting exposure can have stronger influence on the mechanical properties of the stone veneers and will be different based on the geographic location and climatic condition. While the standard EN 13919:2002 [16] provides test method for intensive acid attack on stone, researchers used varied test procedures to simulate test environment appropriate for the prevalent local conditions. In-fact, [17], [15], [18] used 3 weeks; 1, 3, 7 and 14 days; and 5 days periodic wetting, respectively in their research. The periodic wetting does not truly reflect the situation experienced by the cladding panels in the real environment, as rainwater or cleaning water seldom deposits on the panel surface except as droplets due to localised imperfections on the panel surface. Instead rainwater 
comes in-contact with the panel surface in frequent cycles and runoff from the surface, possibly transporting any deposit away from the surface. Different acid solution of $\mathrm{pH}=-1 \sim 5.6$ were used to simulate the wetting acid solution, for example [15], [18] and [19] used acid solutions of $\mathrm{pH}$ value 5.6, 4.5 and, - 1 and 3 , respectively. It was also reported that distilled water with $\mathrm{pH}=6.5$ caused considerable material loss in calcareous stones [18]. Several researcher concluded that $\mathrm{pH}=4 \sim 5$ represent the environment of the major European [20] and Australian [21] cities. The accelerated WDC used in this research is an innovative method that suits the Australian conditions.

The effects of WDC on the flexural strength of three commonly used Australian granite cladding panels are investigated in this paper. This work compliments a previous investigation on the effect of FTC on the same three types of Australian granite [5]. The specimens were manually subjected to WDC, where the effect of wetting the samples in tapwater and acidified solution and drying is evaluated. The drying cycles were achieved through a controlled heating chamber. Based on the test results, the effect of WDC on strength is assessed and a correlation between UPV and strength of WDC weathered granite specimens is proposed.

\section{Experimental Program}

In this section WDC weathering, destructive and non-destructive tests of the thin granite cladding specimens are presented and discussed.

\subsection{Material Description}

Three common Australian granite types; Calca, Imperial Black (or Adelaide Black) and Grandee were used in this study. Petrographic description of the selected granite types is summarised in Table 1. Key features of these three stones are high compressive strength, hardness, durability, visible crystalline structure with interlocking crystals of medium to coarse grain and highly polished surfaces. The stones can be distinguished by their appearances as shown in Fig. 1.

\subsection{Test Specimens and Accelerated Wetting-Drying Cycles (WDC)}

Total 45 specimens, 15 for each granite type were randomly selected from a pile of granite coupons which were stacked outdoors under exposure to natural weather conditions. The nominal dimensions of a typical coupon is: $400 \times 100$ $\times 30 \mathrm{~mm}$ (length $\times$ width $\times$ thickness). Only one face $(400 \times 100 \mathrm{~mm})$ of each coupon is polished. The specimens were grouped into three batches: tapwater, acidified and control groups. A total of 30 specimens (10 of each stone type, S1-S10) were subjected to the WDC while another 15 control specimens (5 of each stone type, C1-C5) were preserved as the unweathered reference. Each specimen was weighed and, their dimensions were carefully checked and recorded according to the flexural test requirements of ASTM C880/C880M [22]. The tapwater and acidified group specimens were then subjected to the WDC in two separate stages. Fig. 2 and Fig. 3 shows the WDC cycles used in the experimental program and the experimental setup, respectively.

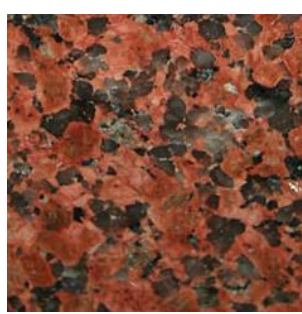

(a)

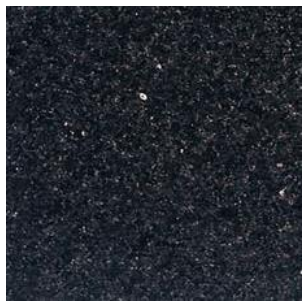

(b)

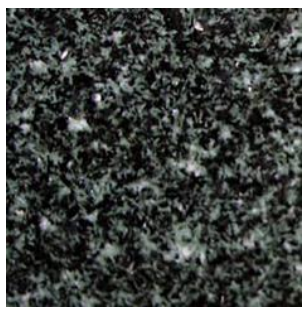

(c)

Fig. 1 Granite types (a) Calca; (b) Imperial Black; (c) Grandee [5]

Fig. 2 (a) shows Stage I of the weathering process that consisted of fifty WDC. In each wetting cycle as shown in Fig. 3(a), the specimens were grouped according to their granite type and were fully immersed in separate tanks of tap water for one hour in room temperature. This process was done manually with fresh tap water used to fill the tanks and was discarded at the end of each wetting cycle. In each drying cycle, the specimens were placed on shelves in a drying chamber as shown in Fig. 3b. Warm air was blown onto the specimens and the temperature in the chamber was maintained at $40{ }^{\circ} \mathrm{C}$ for three to six hours. At the end of the fiftieth cycle, the specimens were left to dry in open air for 48 hours, then weighed. Three specimens from each granite type were randomly selected for an interim UPV test.

Fig. 2 (b) shows Stage II of WDC. In Stage II, tap water was used in wetting cycles for 5 specimens of each granite type while for the remaining 5 specimens acidified water was used in the wetting cycle. Different tanks were used in Stage II for different granite types and groups (i.e., tap water and acidified groups).

Table 1

Petrographic description

\begin{tabular}{|c|c|c|c|c|c|}
\hline Granite Type & Alternative Name & Quarry & Geological Classification & Primary Minerals & Appearance \\
\hline Imperial Black & - Adelaide Black & $\begin{array}{l}\text { - Black Mountain, } 85 \mathrm{~km} \\
\text { North and North-East of } \\
\text { Adelaide }\end{array}$ & - Monzogabbro & $\begin{array}{l}\text { - Plagioclase feldspar } \\
\text { - Pyroxene } \\
\text { - K-feldspar }\end{array}$ & $\begin{array}{l}\text { - Dark black } \\
\text { - Highly polishable. }\end{array}$ \\
\hline Calca & $\begin{array}{l}\text { - Calca Red } \\
\text { - Empire Red } \\
\text { - Dragon Red } \\
\text { - Autumn Brown }\end{array}$ & - Calca, South Australia & - Granite & $\begin{array}{l}\text { - Orthoclase feldspar } \\
\text { - Quartz }\end{array}$ & - Pink/ light reddish \\
\hline Grandee & - Ashcroft Grandee & $\begin{array}{l}\text { - District of Mulliandry, } 38 \\
\mathrm{~km} \text { from Forbes in } \\
\text { central-western NSW. }\end{array}$ & $\begin{array}{l}\text { - Quartz Monzogabbro } \\
\text { - Geologically Devonian } \\
\text { quartz diorite }\end{array}$ & $\begin{array}{l}\text { - Plagioclase feldspar } \\
\text { - Pyroxene } \\
\text { - Quartz (low) }\end{array}$ & $\begin{array}{l}\text { - Dark color } \\
\text { - Highly polishable. }\end{array}$ \\
\hline
\end{tabular}




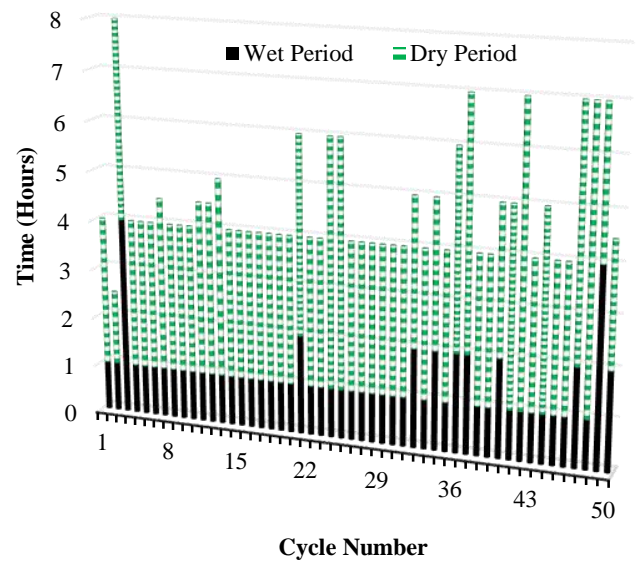

(a)

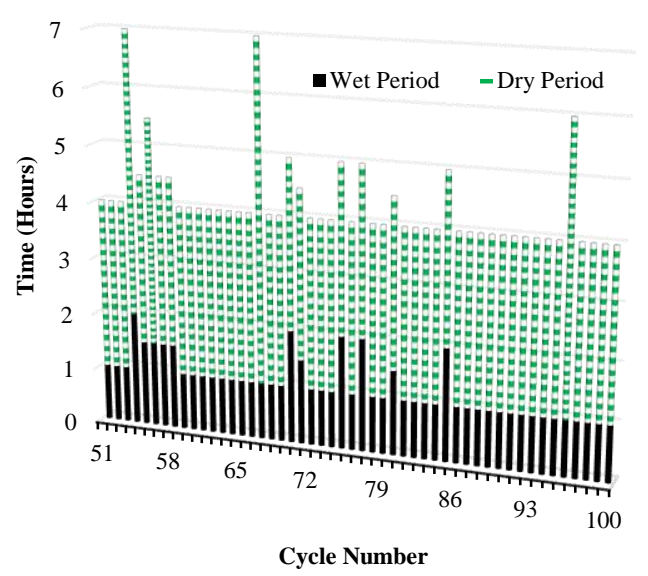

(b)

Fig. 2 Wetting - drying cycles (a) Stage - I; (b) Stage - II

The acidified solution in each tank was a mixture of tap water, $\mathrm{HNO}_{3}$ and $\mathrm{H}_{2} \mathrm{SO}_{4}$. Similar acid solution $\left(\mathrm{H}_{2} \mathrm{SO}_{4}+\mathrm{HNO}_{3}+\mathrm{H}_{2} \mathrm{O}\right)$ and $\left(\mathrm{H}_{2} \mathrm{SO}_{3}+\mathrm{HNO}_{3}+\mathrm{H}_{2} \mathrm{O}\right)$ were also used in [15] and [17], respectively while [18] and [23] adopted a sulphuric acid solution $\left(\mathrm{H}_{2} \mathrm{SO}_{4}+\mathrm{H}_{2} \mathrm{O}\right)$ and a nitric acid solution $\left(\mathrm{HNO}_{3}+\mathrm{H}_{2} \mathrm{O}\right)$, respectively in their studies. It was further reported in [17] that the $\mathrm{HNO}_{3}$ present in the acid solution acted as a catalyser of the $\mathrm{H}_{2} \mathrm{SO}_{3}$ reaction, while the presence of $\mathrm{H}_{2} \mathrm{SO}_{4}$ caused more damage [18]. The acidified solution used in each tank was a mixture of $40.5 \mathrm{~mL}$ of $1.0 \mathrm{M}, \mathrm{HNO}_{3}, 27 \mathrm{~mL}$ of $1.0 \mathrm{M}, \mathrm{H}_{2} \mathrm{SO}_{4}$ and $27 \mathrm{~L}$ of $\mathrm{H}_{2} \mathrm{O}$ (tap water). The $\mathrm{pH}$ of this solution was measured using $\mathrm{pH}$ paper and was maintained at $\mathrm{pH} \approx 4.5$ to simulate typical acid rain. The acidified solution was freshly mixed for each acidified wetting cycle and discarded at the end of each cycle. While researchers [15] and [17] adopted measures to maintain the $\mathrm{pH}$ level during periodic wetting, such measure was not required for the frequent wetting cycles. The ratio of $\mathrm{HNO}_{3}$ to $\mathrm{H}_{2} \mathrm{SO}_{4}$ was based on the concentration of atmospheric $\mathrm{SO}_{2}: \mathrm{NO}_{\mathrm{X}}=1: 2$, that reflect the air quality in a typical Australian urban environment [21] where buildings with external granite cladding are likely to be found.

At the end of the one $100^{\text {th }}$ cycle, the specimens were left to dry in open space for 48 hours then weighed. Full $100{ }^{\circ} \mathrm{C}$ periodic drying similar to those reported in $[15,17,18]$ was avoided, as such high temperature is not an actual representation of the local outdoor climate conditions. Moreover, strong heating cycles [14] would potentially minimise the influence of the wetting cycles.

\subsection{Ultrasonic Pulse Velocity (UPV) Testing}

The UPV test setup consisted of a Panametrics 5077 PR pulser-receiver with two contact transducers and a Tektronix TDS210 LCD oscilloscope. UPV was measured by placing the transducers on the opposite parallel faces of the specimen. The resonance frequency of the transducers was checked against the UPV test requirements of ASTM D2845-05 [24]. The ultrasonic waves were transmitted through the test specimen by transducer-1: acting as the emitter and received by transducer-2: acting as the receiver. Trial UPV test was performed with the transducers coated with Vaseline and generic gel couplant (Sonotech Ultragel II). The generic gel couplant demonstrated improved connectivity with the test specimen which was used throughout the NDT program. UPV measurements were taken along the width and thickness of the specimen, and the average of three independent readings in each direction was recorded.

\subsection{Flexural Strength Testing}

All 45 specimens, including those in the control group, were tested destructively to failure by flexure according to ASTM C880/C880M [22]. A four-point bending test rig placed in Instron 5500R/6027 testing machine was used as shown in Fig. 4. The 4-point bending test was performed on the specimens with a span length (L) of $320 \mathrm{~mm}$, which is 10 times the specimen's thickness. The overall length of each specimen was limited to $400 \mathrm{~mm}$. A rigid steel loading frame was used to facilitate the roller support arrangement; the two point loads $(W / 2$ each) were placed $80 \mathrm{~mm}(L / 4)$ inward from each support and $160 \mathrm{~mm}(L / 2)$ apart from each other. All the specimens were tested with the polished face down, at a monotonic loading rate of $0.05 \mathrm{~mm} / \mathrm{min}$ consistent with ASTM recommendation of $4.14 \mathrm{MPa} / \mathrm{min}$. The maximum applied load was measured from the load cell data, while the length, orientation and the average thickness at the failure plane were measured and recorded at the completion of each test.

The flexural tensile strength $\left(f_{t}\right)$ of the specimen was calculated using eq 1 , where, $W$ is the maximum applied load on the specimen, $L, b$ and $t$ are the length, width and thickness dimensions of the specimen, respectively and $l$ is the actual length of the inclined failure plane across the tension face.

$f_{t}=\frac{3 W L b}{4 l^{2} t^{2}}$

Equation 1 accounts for the fact that the failure plane is usually not perpendicular to the span, which was observed in all 45 granite specimens [5].

\section{Test Results and Discussions}

The test results of the 15 unweathered (control) and 30 weathered specimens are discussed in this section.

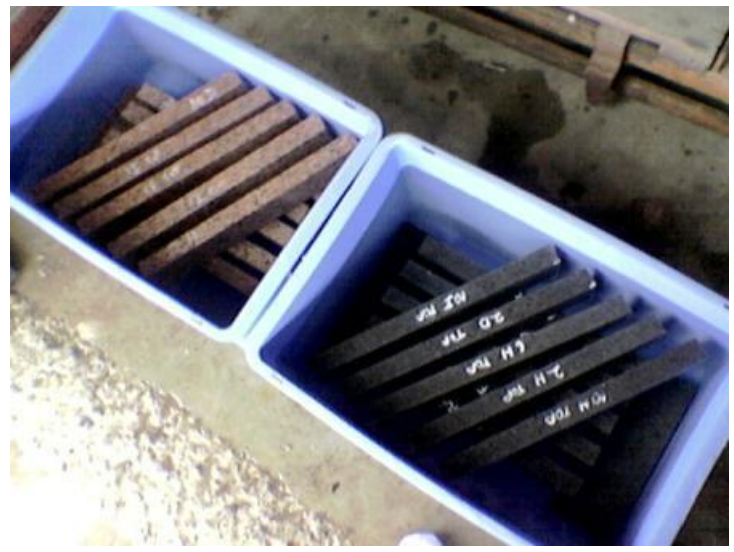

(a)

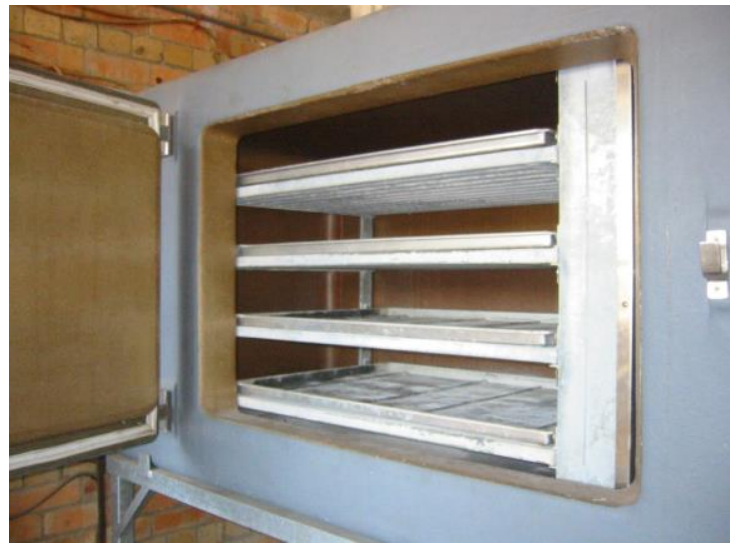

(b)

Fig. 3 Experimental setup (a) Wetting; (b) Drying 


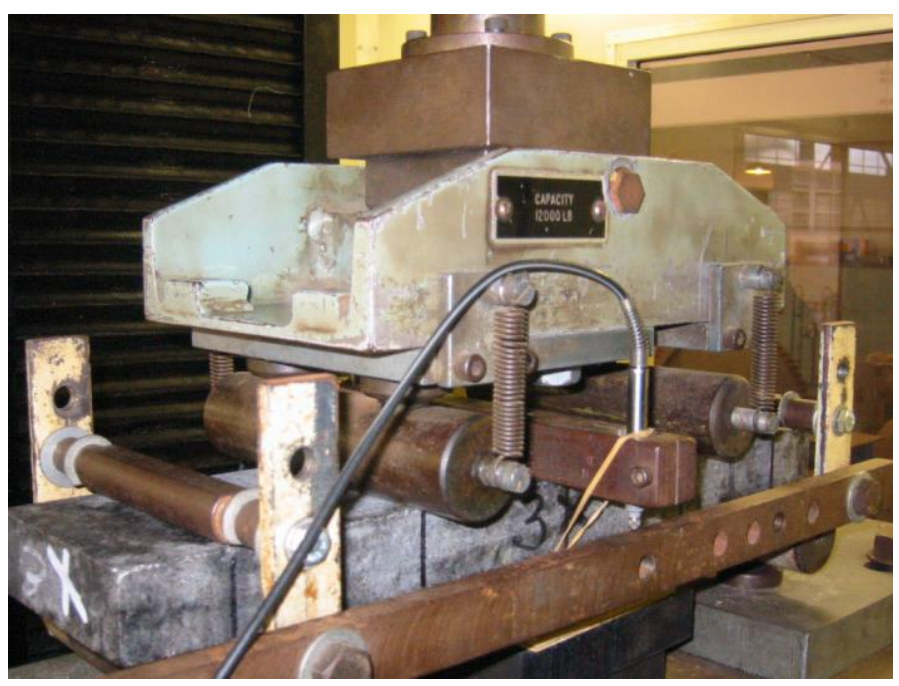

Fig. 4 Four-point bending test arrangement

\subsection{Flexural Strength}

Figs. 5 shows the average flexural strength, $f_{t}$ of the unweathered and weathered granite specimens obtained from the four-point bending tests. The results demonstrate that $f_{t}$ of the Imperial Black, Calca and Grandee control specimens was $16.18 \mathrm{MPa}, 9.73 \mathrm{MPa}$ and $15.11 \mathrm{MPa}$, respectively. For the weathered tap water group specimens, $f_{t}$ was $14.25 \mathrm{MPa}$, 9.99 MPa and 15.43 $\mathrm{MPa}$; while for the acidified group $f_{t}$ was $14.55 \mathrm{MPa}, 9.08 \mathrm{MPa}$ and $15.2 \mathrm{MPa}$, respectively. No simple trend could be established to account for the effect of WDC by tapwater and acidified solution within each granite group. Based on the results shown in Fig. 5, it can be inferred that Imperial Black was the only granite type affected by the WDC. The Imperial Black tapwater group experienced the highest loss in flexural strength of $11.96 \%$. There was a slight loss in flexural strength of Calca acidified group of $6.7 \%$; although the tapwater group shows $2.6 \%$ increase in $f_{t}$. Flexural strength of the weathered tapwater and acidified groups of Grandee increased by $2.2 \%$ and $0.6 \%$, respectively. Factors such as the highly polished surface, grain distribution and porosity of the stones and the accumulation of salts $[17,25]$ may have contributed towards this trend. The non-porous surface of Imperial Black and Grandee samples provided resistance against water and acids attack, whereas the semi-porous surface of Calca allowed deposition and accumulation of salts which may be present in tapwater.

\subsection{Ultrasonic Pulse Velocity (UPV)}

Figs. 6 (a) and (b) show the UPV values for all the Imperial Black specimens measured along the width and the thickness, respectively. UPV is measured at the unweathered state labelled as initial in Fig. 6, and weathered specimens after stage - I and stage - II WDC labelled as interim and tapwater/acidified, respectively. The average UPV of unweathered Imperial Black specimens measured along the width were $5992 \pm 94.32 \mathrm{~m} / \mathrm{s}$ which is consistent with the findings of [5]. It was noticed that the UPV measurements along the width of the specimen was higher than that along the thickness direction. UPV measured across the width of the Imperial Black specimens at the following stages; initial, interim, tapwater and acidified were $16.8 \%, 14.5 \%$, $14.3 \%$ and $14.4 \%$ higher than that of the respective measurements taken across the thickness of the specimen. Variation in UPV due to WDC was insignificant, interestingly some of the weathered specimens showed slightly higher UPV value over their unweathered counterpart.

Fig. 7a-c show the average UPV values of the Imperial Black, Calca and Grandee specimens at different stages of weathering. The average UPV values measured along the width and thickness of the specimens are shown in Table 2. Larger standard deviation is observed among the UPV measurements across the thickness of the specimen, than that of the width. The UPV readings were the most consistent within Imperial Black specimens, while readings taken on Grandee specimens showed the highest variation. No difference was expected between the average UPV values of tapwater and acidified groups of each granite type in the initial and interim stages, as they were subjected to identical conditions. However, following Stage - II WDC, differences in UPV values emerged. The average UPV of the acidified group of Calca and Grandee specimens were $0.49 \%$ and $0.89 \%$ higher than that of the tapwater group, while it was $0.3 \%$ lower for the Imperial Black specimens.

\subsection{Variations in Weight, $U P V$ and $f_{t}$ due to WDC}

Fig. 8 (a) shows the variation in weight and UPV experienced by the granite specimens at different stages of the WDC, where the positive and negative variation represent the gain and loss in the parameters, respectively. Samples were weighed before the WDC and after the $50^{\text {th }}$ and $100^{\text {th }}$ cycle. The weight losses of the granite specimens were small. Only the Calca acidified group specimens experienced an average weight loss of $1.34 \%$ (equivalent to $47 \mathrm{~g}$ of material). No definitive weight loss pattern could be established. It was also found that several specimens from all granite types experienced slight gain in weight $(0.3-0.65 \%)$ which is consistent with those reported in [17, 26]. Many sources such as incomplete desiccation of samples, change in chemistry of the constituent minerals, accumulation of salt introduced from the immersion liquids during the wetting cycles could contribute to the increase in the weight of the granite specimens.

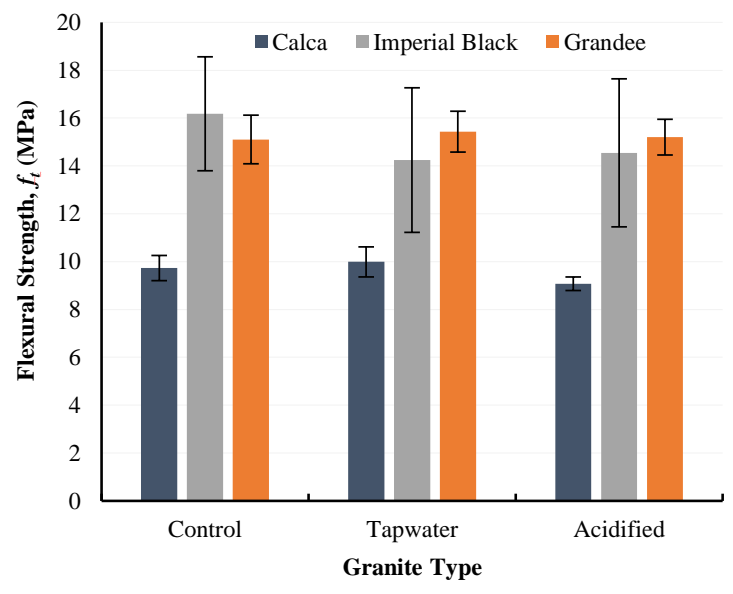

Fig. 5 Flexural strength of granite specimens

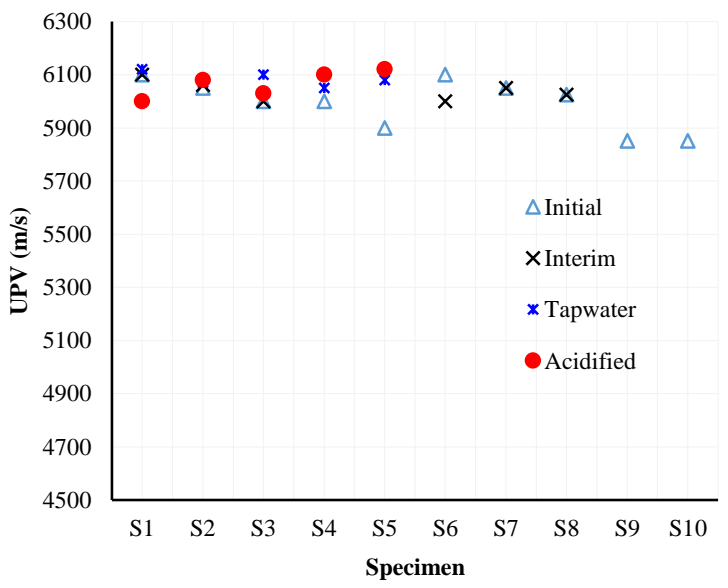

(a)

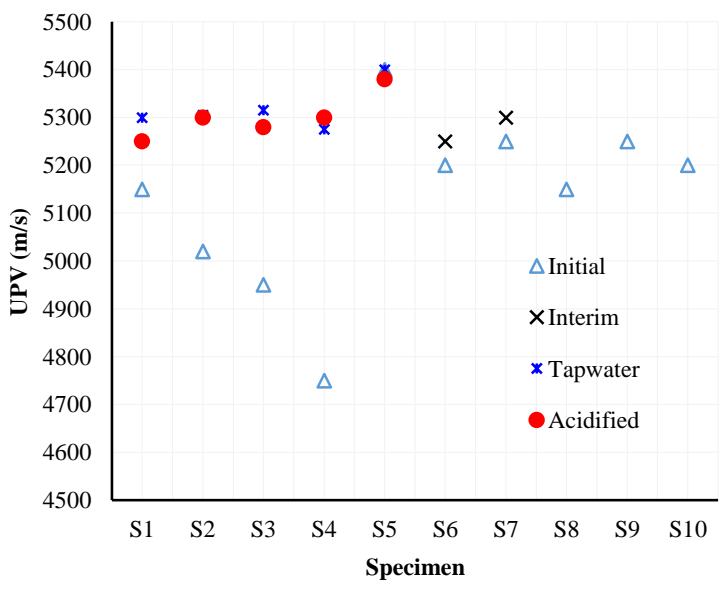

(b)

Fig. 6 UPV of Imperial Black specimens measured along (a) Width; (b) Thickness 
Table 2

Average UPV of unweathered and weathered specimens

\begin{tabular}{|c|c|c|c|c|c|c|c|c|}
\hline \multirow[t]{2}{*}{ Granite Type } & \multicolumn{2}{|c|}{$\mathrm{UPV}_{\text {Unweathered }}(\mathrm{m} / \mathrm{s})$} & \multicolumn{2}{|c|}{$\mathrm{UPV}_{\text {Interim }}(\mathrm{m} / \mathrm{s})$} & \multicolumn{2}{|c|}{$\mathrm{UPV}_{\text {Tapwater }}(\mathrm{m} / \mathrm{s})$} & \multicolumn{2}{|c|}{$\mathrm{UPV}_{\text {Acidified }}(\mathrm{m} / \mathrm{s})$} \\
\hline & Width & Thickness & Width & Thickness & Width & Thickness & Width & Thickness \\
\hline Calca & $4553 \pm 32.3$ & $4236.8 \pm 314.9$ & $4576.25 \pm 70.3$ & $4926.7 \pm 55.1$ & $4534 \pm 27$ & $4332 \pm 66.1$ & $4556 \pm 41.7$ & $4432 \pm 80.2$ \\
\hline Grandee & $5459 \pm 303.2$ & $4885 \pm 178.65$ & $5408 \pm 307.5$ & $4950 \pm 20$ & $5408 \pm 307.5$ & $4820 \pm 278.4$ & $5456 \pm 293.9$ & $4880 \pm 301.2$ \\
\hline
\end{tabular}

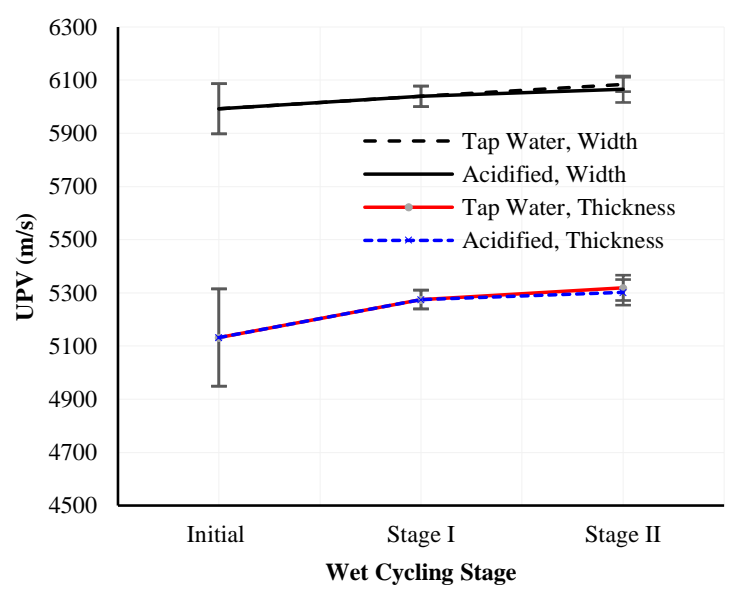

(a)

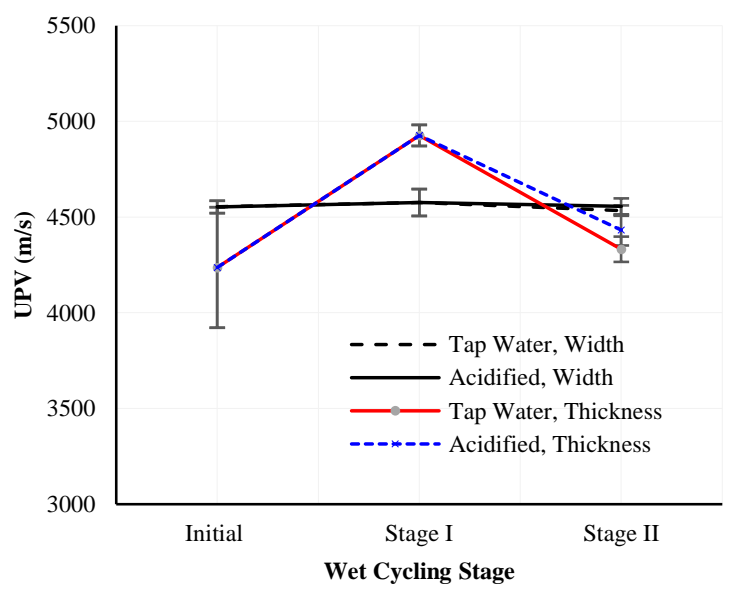

(b)

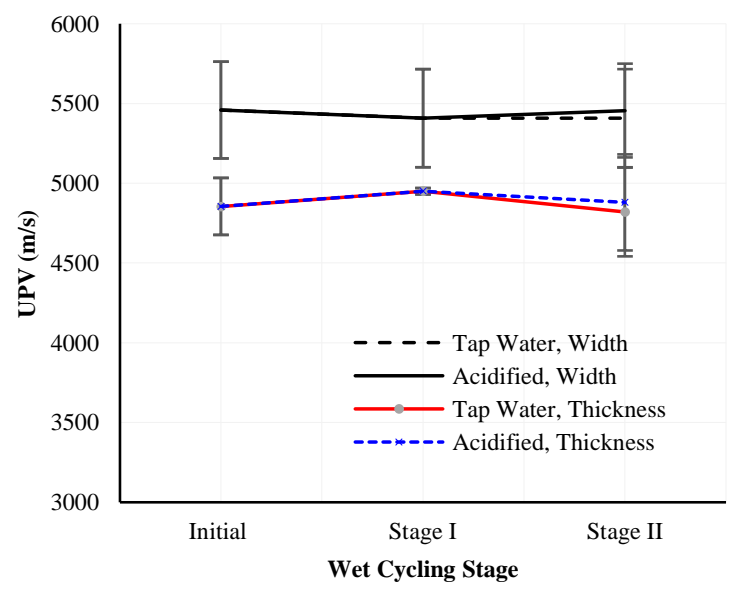

(c)

Fig. 7 Average UPV of unweathered and weathered specimens (a) Imperial Black; (b) Calca; (c) Grandee

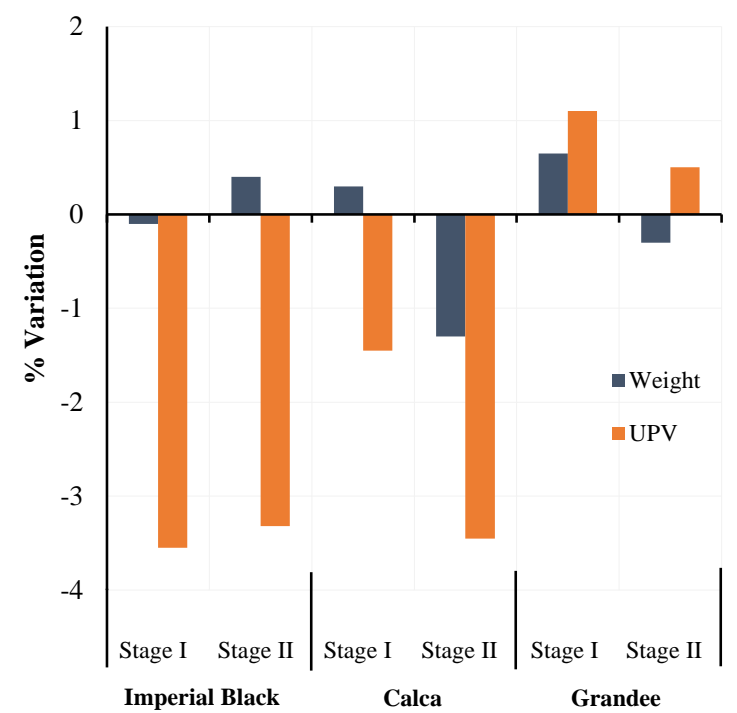

(a)

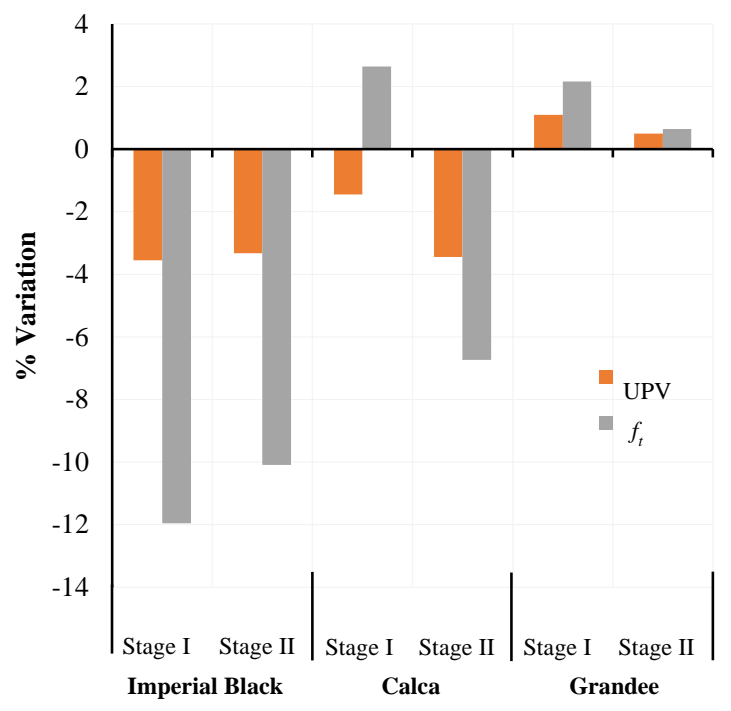

(b)

Fig. 8 Percentage loss (a) Weight and UPV; (b) Flexural Strength and UPV

Loss in the UPV value in response to the WDC was more prominent than the loss in weight of the specimen. Although no consistent relation could be established between the losses in weight and the losses in UPV. The maximum loss in UPV was recorded for the Imperial Black specimens of $3.55 \%$, after the stage - I weathering, while the acidified group of Calca specimens endured an average UPV loss of $3.45 \%$ after the WDC. On the contrary, the tapwater and acidified group Grandee specimens experienced an average UPV gain of $1.1 \%$ and $0.5 \%$, respectively.

Fig. 8(b) shows losses in UPV and $f_{t}$ experienced by the granite specimens at different stages of WDC. The loss in $f_{t}$ under WDC is higher compared to the loss in UPV. The Imperial Black specimens after the stage - I weathering showed an average $11.96 \%$ loss in $f_{t}$. A similar trend between UPV and $f_{t}$ is 
observed for Imperial Black and the Grandee specimens unlike that for the Calca specimens. The tapwater group Calca and Grandee specimens experienced an average gain in $f_{t}$ of $2.64 \%$ and $2.16 \%$, respectively. According to Fig. 8(b) the Grandee specimens were the least affected by the WDC.

Fig. 9 shows the variation in $f_{t}$ and UPV of the granite specimens following stage - I and - II WDC, and the same following FTC weathering reported in [5]. The Fig. shows that losses in $f_{t}$ and UPV of the granite specimens was more pronounced under FTC than under WDC. The Imperial Black specimens experienced an average loss in $f_{t}$ of $28.56 \%$ due to FTC, which is 2.39 times higher than the losses due to WDC.

\subsection{Correlation between UPV in the Width and Thickness Directions}

Linear correlation between UPV values measured along the width and the thickness direction of the granite specimens is shown in Fig. 10 and given by eq 2 with $\mathrm{R}^{2}=0.709$. The developed relation in eq 2 can be used to predict the UPV value of granite panels along the width when measurement is only possible in the thickness direction.

$$
U P V_{\text {Width }}=1.103 U P V_{\text {Thickness }} ? 45.709
$$

\subsection{Correlations between UPV and Tensile Strength}

Fig. 11 shows the relation between $f_{t, W D C}$ obtained from destructive test and measured UPV along the width of all 45 unweathered and weathered (i.e., tapwater and acidified groups) granite specimens from the WDC testing. Based on the obtained results, a linear correlation is established as shown in Fig. 11 and eq 3 with $\mathrm{R}^{2}=0.57$ that can be used to predict the on-site $f_{t, W D C}$ of the granite cladding panels by means of the measured pulse velocity.

$$
f_{t, W D C}=0.0041 U P V_{\text {mean }} ? 8.55
$$

Based on the FTC weathering results the correlation between $f_{t, F D C}$ and UPV of unweathered and weathered granite specimens was reported in [5] as,

$$
f_{t, F T C}=0.0041 U P V_{\text {mean }} ? 9.6345
$$

Performance of the proposed eq 3 for the flexural tensile strength $f_{t, W D C}$ is compared against eq 4 and those proposed by other researchers [8] for the direct tensile strength $\sigma_{t}$ (eq 5). A range of UPV between $3000 \mathrm{~m} / \mathrm{s}$ to $6500 \mathrm{~m} / \mathrm{s}$ was selected for the comparison.

$$
\sigma_{t}=0.701 e^{(0.00052 U P V)}
$$

Fig. 12 shows the predicted tensile strength $\left(f_{t, W D C}, f_{t, F D C}\right.$ and $\left.\sigma_{t}\right)$ using Eqs (3), (4) and (5) against the corresponding UPV values, and the results seems reasonable.

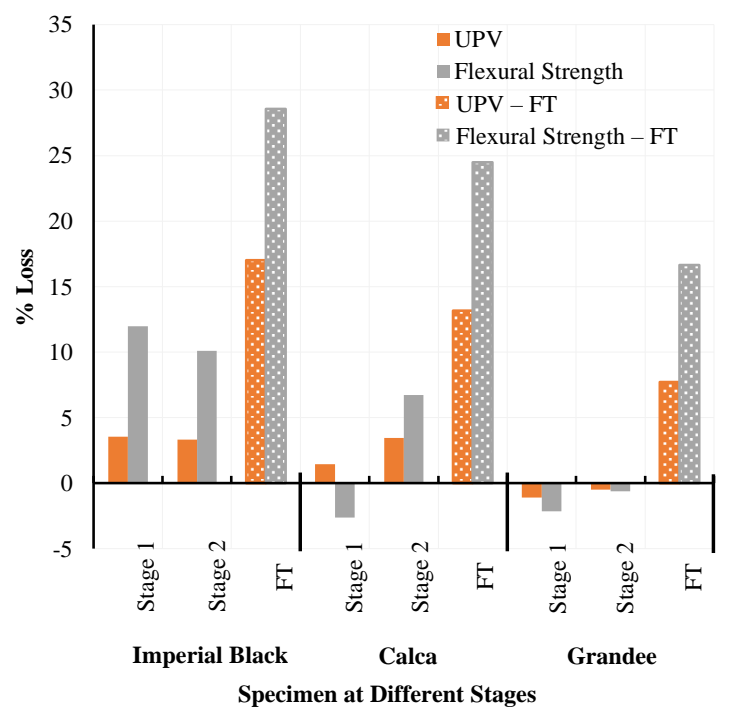

Fig. 9 Percentage loss due to WDC and FTC

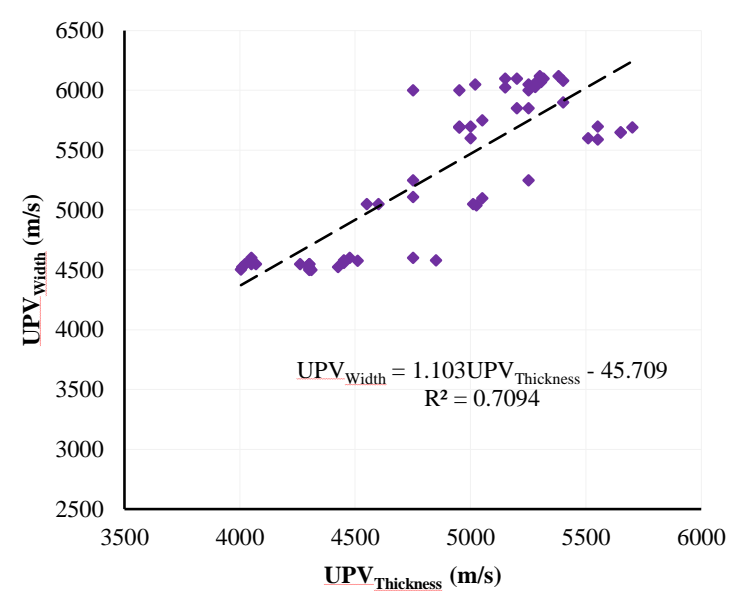

Fig. 10 Correlation between UPV along width and thickness of specimen

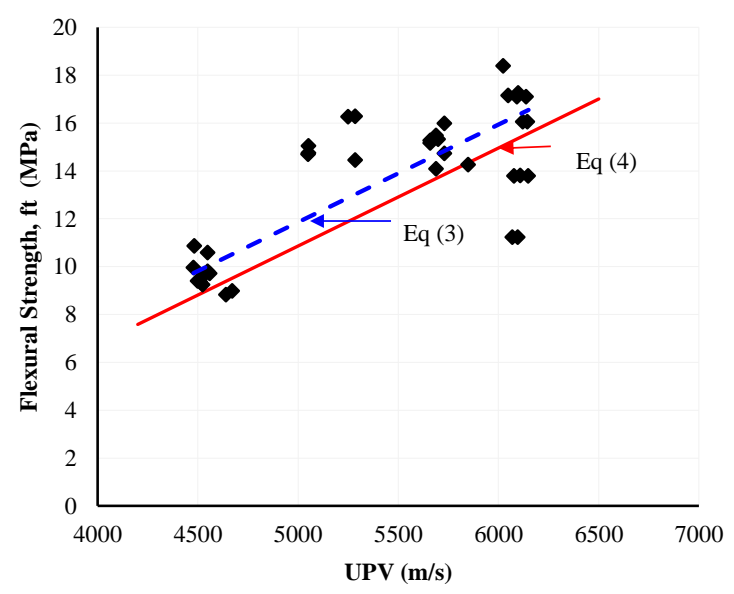

Fig. 11 Correlation between UPV and flexural strength

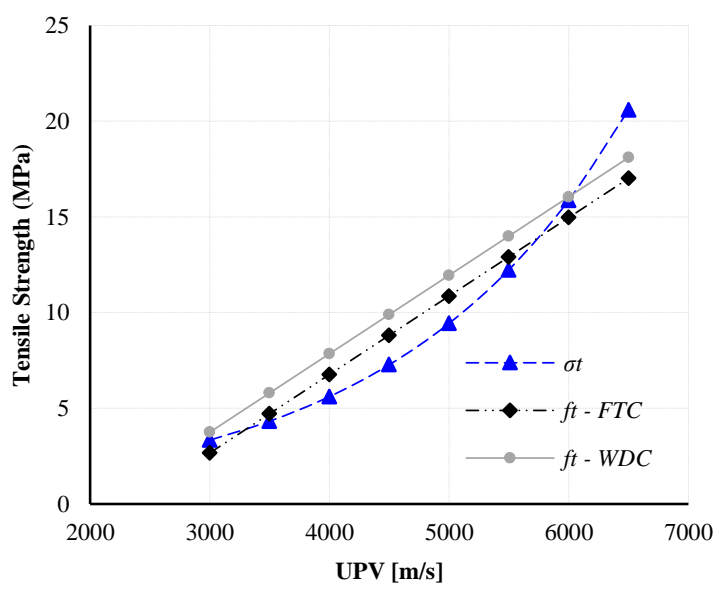

Fig. 12 Predicted direct and flexural tensile strength using UPV

\section{Conclusions}

The effect of accelerated weathering through WDC on thin granite cladding panels commonly used on high-rise buildings is reported in this paper. A total of 45 specimens, 15 each of Calca, Imperial Black and Grandee type Australian granites were used in the experimental program. The specimens were subjected to total of 100 cycles of wetting and drying in two separate stages. In stage - I, total 30 specimens, 10 from each granite type was divided in two identical groups namely tapwater and acidified, and were subjected to $50 \mathrm{WDC}$, where the wetting cycles were conducted in tap water. In stage - II, the tapwater and the acidified group specimens from the stage - I weathering, were separately subjected to the next 50 wetting cycles in tapwater and an acidified solution of $\mathrm{pH} \approx 4.5$, respectively. All the drying cycles were conducted using a controlled drying chamber. UPV was measured along the width and thickness 
of the unweathered and weathered specimens. All 30 weathered and 15 unweathered control specimens underwent destructive flexural testing to determine the flexural tensile strength.

The WDC test results showed slight changes in strength of the granite specimens according to UPV and destructive testing. While the Imperial Black and Calca specimens showed small decline in the flexural strength, no changes were noticed in-case of the Grandee specimens. Such behaviour is accompanied by the losses in weight and measured UPV. Difference in UPV measured along the width and thickness of the specimen gives indication of the material anisotropy of the granite specimens.

The WDC test results were compared with those obtained from the FTC test [5]. It is concluded that Imperial Black and Grandee is the most and the least affected granite cladding panel type under weathering. The reduction in flexural tensile strength of Imperial Black specimens under WDC is 2.39 times lower than that under FTC. A correlation between UPV and flexural strength of unweathered and weathered granite is established, which is slightly different to that obtained from the FTC test program. This can be particularly useful in onsite assessment of granite cladding panels during the service life of the primary steel structure.

\section{Acknowledgements}

The authors would like to acknowledge the assistance of Adrian Lau and Gerrit Lebbink in conducting the experimental work and Dr R. Blackwell for his comments and discussion.

\section{References}

[1] Blackwell R., "No Stone Unturned: Towards the Design of Thin Structural Stone Veneers $\mathrm{PhD}$ Thesis, University of Queensland, 2005.

[2] Royer-Carfagni G., "Some considerations on the warping of marble facades: the example of Alvar Aalto's Finland Hall in Helsinki", Construction and Building Materials, 13(8), 449457, 1999 .

[3] Mauko A., Mirtiè B., Mladenoviè A. and Grelk B., "Deterioration of the granodiorite façade case example Maximarket, Ljubljana Propadanje granodioritne fasade tudijski primer Maximarket, Ljubljana", RMZ-Materials and Geoenvironment, 53(1), 23-37, 2006.

[4] Pires V., Rosa LG. and Dionisio A., "Implications of exposure to high temperatures for stone cladding requirements of three Portuguese granites regarding the use of dowel-hole anchoring systems", Construction and Building Materials, 64, 440-450, 2014.

[5] Noor-E-Khuda S., Albermani F. and Veidt M., "Flexural strength of weathered granites: influence of freeze and thaw cycles", Construction and Building Materials, 156, 891-901, 2017.

[6] Colombo I.S., Main I. and Forde M., "Assessing damage of reinforced concrete beam using "b-value" analysis of acoustic emission signals", Journal of Materials in Civil Engineering ASCE, 15, 280-286, 2003.

[7] Cerrillo C., Jiménez A., Rufo M., Paniagua J. and Pachón F., "New contributions to granite characterization by ultrasonic testing", Ultrasonics, 54, 156-167, 2014.

[8] Vasconcelos G., Lourenço P., Alves C. and Pamplona J., "Ultrasonic evaluation of the physical and mechanical properties of granites", Ultrasonics, 48, 453-466, 2008.

[9] Vasanelli E., Colangiuli D., Calia A., Sileo M. and Aiello M.A., "Ultrasonic pulse velocity for the evaluation of physical and mechanical properties of a highly porous building limestone", Ultrasonics, 60, 33-40, 2015

[10] Chen J., Xu Z., Yu Y. and Yao Y., "Experimental characterization of granite damage using nonlinear ultrasonic techniques", NDT \& E International, 67, 10-16, 2014.

[11] Baldock T.E., Karampour H., Sleep R., Vyltla A., Albermani F., Golshani A., Callaghan D.P., Roff G. and Mumby P.J., "Resilience of branching and massive corals to wave loading under sea level rise-A coupled computational fluid dynamics-structural analysis", Marine Pollution Bulletin, 86(1), 91-101, 2014.

[12] Barbera G., Barone G., Mazzoleni P. and Scandurra A., "Laboratory measurement of ultrasound velocity during accelerated aging tests: Implication for the determination of limestone durability", Construction and Building Materials, 36, 977-983, 2012.

[13] Cardani G., Cantini L., Munda S., Zanzi L. and Binda L., "Non-invasive measurements of moisture in full-scale stone and brick masonry models after simulated flooding: effectiveness of GPR", Non-destructive Testing of Materials and Structures: Springer, 1143-1149, 2013.

[14] Franzoni E., Sassoni E., Scherer G.W. and Naidu S., "Artificial weathering of stone by heating", Journal of Cultural Heritage, 14, 85-93, 2013.

[15] Franzoni, E. and Sassoni, E., "Correlation between microstructural characteristics and weight loss of natural stones exposed to simulated acid rain", Science of the Total Environment, 412, 278-285, 2011.

[16] CEN (European Committee for Standardisation), EN 13919: Natural Stone Test Methods. Determination of Resistance to Ageing by SO2 Action in the Presence of Humidity, CEN, Brussels, 2002.

[17] Vazquez P., Carrizo L., Thomachot-Schneider C., Gibeaux S. and Alonso F.J., "Influence of surface finish and composition on the deterioration of building stones exposed to acid atmospheres", Construction and Building Materials, 106, 392-403, 2016

[18] Tecer L., "Laboratory experiments on the investigation of the effects of sulphuric acid on the deterioration of carbonate stones and surface corrosion", Water, Air \& Soil Pollution, 114(1), 1-12, 1999.

[19] Alkattan M., Oelkers E.H., Dandurand J.L. and Schott J., "An experimental study of calcite and limestone dissolution rates as a function of $\mathrm{pH}$ from- 1 to 3 and temperature from 25 to $80{ }^{\circ} \mathrm{C} "$, Chemical Geology, 151(1), 199-214, 1998.

[20] Anatolaki C. and Tsitouridou R., "Relationship between acidity and ionic composition of wet precipitation: a two years study at an urban site, Thessaloniki, Greece", Atmospheric Research, 92(1), 100-113, 2009

[21] Australian Environment Council, Acid Rain in Australia: a National Assessment, AEC Report no.25, Australian Government Publishing Service, Canberra, Australia, 1989.

[22] ASTM.C880/C880M-15, Standard Test Method for Flexural Strength of Dimension Stone, American Society for Testing and Materials, 2015

[23] Xie S., Qi L. and Zhou D., "Investigation of the effects of acid rain on the deterioration of cement concrete using accelerated tests established in laboratory", Atmospheric Environment, 38(27), 4457-4466, 2004

[24] ASTM.D2845-05, Standard Test Method for Laboratory Determination of Pulse Velocities and Ultrasonic Elastic Constants of Rock, American Society for Testing and Materials, 2005.

[25] Alonso F.J., Vázquez P., Esbert R.M. and Ordaz J., "Ornamental granite durability: evaluation of damage caused by salt crystallization", Materiales de Construcción, 58(289290), 191-201, 2008

[26] Winter G.M., "Determination of the Design Strength of Thin Structural Veneer Cladding Panels", PhD Thesis, University of Queensland, Brisbane, Australia, 2002. 